\title{
Book Review: Bats in the Anthropocene: Conservation of Bats in a Changing World
}

Bats in the Anthropocene - Conservation of Bats in a Changing World gives its readers a touch of hope: human habitats are quite valuable for conservation, or can be so, as long as they are properly planned.

VOIGT, Christian C., E KINGSTON, Tigga (Eds.). 2016. Bats in the Anthropocene: Conservation of Bats in a Changing World. Springer Nature, 601 p. ISBN 978-3-319-25218-6 - ISBN 978-3-319-25220-9 (eBook).

Fabio Angeoletto fabio_angeoletto@yahoo.es https:/ / orcid.org/0000-0002-3084-3928 Programa de Pós-Graduação em Geografia da UFMT, campus de Rondonópolis

Isabela Caroline Ortencio Negri https:/ / orcid.org/0000-0002-1821-4213 isabelaortencio@gmail.com Programa de Pós-Graduação em Geografia da UFMT, campus de Rondonópolis

Juciane Maria Johann https:/ / orcid.org/0000-0001-6943-2555 jucijohann@yahoo.com.br

Programa de Pós-Graduação em Geografia da UFMT, campus de Rondonópolis

Oristian C. Vsigt - Tigga Kingston Edotors

\section{Bats in the}

Anthropocene: Conservation of Bats in a Changing World
Summarizing the main threats bats face in a world undergoing fast changes, and how to overcome these threats and conserve bat species in anthropogenic landscapes, are the main aims of the book organized by Christian C. Voigt and Tigga Kingston. The book is composed of 18 chapters, i.e., the introduction and seventeen more chapters divided into four parts.

The authors are careful at defining the Anthropocene as a possible new geological era that has succeeded the Holocene, although such a statement remains the object of debates in the academic community. The Anthropocene was unexpectedly triggered by humans and had several consequences such as the sixth massive extinction of global biodiversity. Land-use 
change, urbanization, hunting and persecution, mining, and human expansion in their habits are the main threats for bats in the new geological era.

The first part of the book "Bats in Anthropogenically Changed Landscapes" approaches the impacts on, and challenges to the conservation of, bat populations in urban and rural landscapes, as well as in areas changed by road construction-sites. Bats likely comprise the most diversified group of mammals remaining in urban zones. Unfortunately, our understanding of how other wild animals, including bats, respond to the complex urbanization process, remains limited. However, large forest parks can compensate for habitat losses caused by urbanization and, therefore, mitigate the negative impacts imposed on bats at a regional scale. The light pollution observed in cities can cause interspecific competition among bats, since bat species sensitive to light can be excluded from resources explored by light-tolerant species. Urban and rural water sources, such as ponds, can be polluted; therefore, mitigating these impacts demands environmental planning and management. For example, light pollution can be minimized by a design focused on guiding light downwards.

Habitat loss, barrier effect, and run overs are the main impacts resulting from the construction of roads. Selecting a route to avoid important bat habitats is the first step of conservation strategies focused on minimizing the impact of a new road. However, routes that better preserve bats may not fulfill human social and economic criteria, mainly if conservation is undervalued. Rural landscapes presenting vegetation corridors, hedges, riparian forests, and scattered trees host more bat species than secondary forests and landscapes with low tree cover. Rural areas can, therefore, support the Chiroptera fauna.

The second part of the book ('Emerging Diseases') is an overview of a lethal disease affecting millions of bats, the so-called "bat white-nose syndrome", which is an infectious disease caused by a pathogenic fungus. Alternatives to control such infection include the construction of artificial hibernacles that can be cleaned and sanitized every summer, between hibernation seasons.

On the other hand, recent viral outbreaks of zoonotic diseases, which identify bats as the supposedly natural hosts of viruses such as SAR-CoV-2, make the efforts to conserve bats even harder to be put in place. It is of paramount importance preventing contamination with many viral diseases transmitted by bats since such diseases record high lethality rates in humans. Reducing the risk of zoonotic virus outbreaks can also lead to more positive attitudes towards bats, and this process can even be broadened if the ecological importance of pollinators, seed dispersers, and agricultural pest controllers is highlighted.

The third part of the book ("Human-Bat Conflicts and Conservation Approaches") introduces some conflicts between humans, their technologies, and chiropters. For instance, a large number of bats have been killed in wind power facilities worldwide, and it is a reminder of the fact that there are no alternatives to generate energy without generating environmental impacts.

Hunting is another important conflict that affects $13 \%$ of bat species. However, it can be mitigated through gun and ammunition control and the legal protection of shelters 
and caves. Bats who rest and nest in caves are most vulnerable to disturbances. Gates to stop humans' access to them can prevent such disturbances.

Human beings have been sharing buildings with bats for thousands of years. Many bat species can be defined as synanthropic, i.e., they have a strong ecological association with human beings. A synanthropic lifestyle can lead to direct benefits to bats. For example, bats can use human buildings as the path to explore new habitats, which would allow their geographic distribution expansion. However, their coexistence with human beings also brings along some risks; bats can be exposed to pollutants, and shelters in urban zones can be transitory due to city expansion, as well as to the construction and deconstruction of built-up areas. Artificial shelters can replace the lost ones; moreover, urban planning can enable different support-types to flying mammals, such as drinking water sources.

Environmental disservices, such as damages to commercial fruit cultures, can be mitigated through the use of exclusion networks that concern fruit trees and work as a barrier to bats. However, these networks are expensive and their implementation can demand governmental subsidies, mainly in small properties around the world.

Finally, the fourth part of the book ("Educational and Outreach Programs") highlights the importance of taxonomists for species identification. It is impossible to manage wildlife without differentiating species. It is essential for creating conservation networks based on species identification in a given ecosystem or biome. Such networks build social capital, enhance coordination, and lead to effective conservation actions by bonding several social actors, individuals, and groups within space and time due to joint research and action goals.

The social dimension of conservation efforts is evidenced by the $18^{\text {th }}$ and last chapter of the book. There is no doubt that this is the most important chapter for biologists and correlated professional fields. Conservation biologists and other natural scientists oftentimes do not have knowledge and training to implement strict studies on the human dimensions of bat conservation, but these studies are essential for successful conservation plans applied to flying mammals. Conservation biologists must adopt an interdisciplinary approach and work in partnership with social sciences researchers who have such skills and knowledge about this new geological era, which is defined by human actions and their consequences. Research teams and actions to conserve bats must encompass social and natural sciences professionals.

We recommend improving the graphics in an eventual second edition of the book, as well as using more figures to substantiate the text in the chapters. A good graphic project is particularly relevant for books such as the present one, which focuses not only on biologists but also on environmental sociology researchers.

Given their importance, four messages were outspread throughout the book. There is a huge gap in bats' behavioral, ecological, and physiological responses to biospheric scale changes in land use. The enhanced understanding of bats' responses to changes in land use will be a little use for society unless it can the translated into management practices capable of assuring its conservation in the long-run and the provision of critical ecosystem services provided by flying mammals. The book Bats in the Anthropocene - Conservation of Bats in a Changing World gives its readers a touch of hope: human habitats are quite 
valuable for conservation, or can be so, as long as they are properly planned. Nevertheless, the most important message of the book is that the planning of human habitats for the conservation of biodiversity demands the indispensable collaboration between the social sciences and the natural sciences.

\section{ACKNOWLEDGMENTS}

Thanks to Flora Essy Angeoletto and Isabel Cristina Johann Budtinger for the inspiration. May they grow up in a bat-friendly world!

Data de submissão: 14/ago./2020

Data de aceite: $08 /$ nov./2020 